\title{
Performance Evaluation of Concrete Manufactured with Precoated Recycled Fine Aggregates Using Supplementary Cementitious Materials
}

\author{
Wei-Ting Lin* \\ Department of Civil Engineering, National Ilan University, \\ No. 1, Sec. 1, Shennong Rd., Yilan City, Yilan County 260, Taiwan
}

(Received May 25, 2017; accepted December 5, 2017)

Keywords: reclaimed fine aggregate, precoated aggregate, slag, durability

In this study, fly ash and ground granulated blast-furnace slag were applied over fine recycled aggregates in layers of 0.2 and $0.4 \mathrm{~mm}$. We then evaluated the resulting concrete with regard to freshness, mechanical properties, and durability. The fine recycled aggregates (coated and uncoated) were used to replace $25 \%$ of the natural fine aggregates in two water-cement (w/ c) ratios of 0.4 and 0.6 . The coating of recycled aggregates with fly ash was shown to improve the workability of the concrete, regardless of the w/c ratio. Coating recycled aggregates with slag was shown to slightly reduce the workability of the concrete. A fly ash coating was shown to slightly increase the compressive strength of concrete, whereas a slag coating markedly improved compressive strength beyond that of the original concrete. Our results indicate that coating recycled aggregates with furnace slag is an effective approach to enhance the mechanical properties and durability of recycled concrete.

\section{Introduction}

Recycled aggregates comprise ground natural aggregates with attached cement paste, which results in a lower specific gravity, higher porosity, higher absorption, and higher abrasion rate. This can affect the strain characteristics (elasticity, shrinkage, and creep), mechanical properties (compressive and splitting strength), and durability. Crushing processes can be modified to remove surface-adhered cement paste and thereby improve the quality of reclaimed aggregates. ${ }^{(1)}$

Poured concrete is meant to flow around the surface layer of the aggregates, which results in the formation of a water film owing to the concrete's low specific gravity, causing a higher surface water gel on the aggregate surface than concrete in other places [formed as the interfacial transition zone (ITZ)]. An ITZ of 20 to $40 \mu \mathrm{m}$ can greatly affect the mechanical properties and durability of concrete, and the effects are more pronounced in concrete made using recycled aggregates. The formation of an ITZ increases the volume of pores and leads to the formation of microcracks between the aggregate and the hydrated cement paste. ${ }^{(2,3)}$

Cement-based composites such as pozzolanic material (silica fume, furnace slag, fly ash)

${ }^{*}$ Corresponding author: e-mail: wtlin@niu.edu.tw

http://dx.doi.org/10.18494/SAM.2018.1747 
and fibers (glass fiber, carbon fiber, steel fiber) have been added to admixtures to improve the microstructures of ITZ. ${ }^{(4-7)}$ Pozzolanic reactions fill the pores to produce a more compact composite, whereas the inclusion of the fibers improves the tensile properties, crack resistance, and other mechanical properties. ${ }^{(8)}$

Most previous studies in this area have focused on coarse reclaimed aggregates. ${ }^{(9-11)}$ Relatively little research has been carried out to evaluate the effects of adding reclaimed fine aggregates (RFA) as a replacement for natural fine aggregates (NFA). In this study, we focused on the coating of fine aggregates with slag and/or fly ash to improve the weak surface properties of ITZ in concrete. The measurements of ultrasonic velocity (USV) can be used as a sensor to conduct the mechanical properties of the recycled concrete with several variables. Experiments for the determination of flash property, mechanical properties (compressive strength and USV), and durability (absorption and initial surface absorption) were conducted and the results were evaluated.

\section{Materials and Methods}

\subsection{Materials and design mix}

The mix designs used in this study were formulated in accordance with American Concrete Institute (ACI) 211.1 guidelines. RFA was coated with 0.2 and $0.4 \mathrm{~mm}$ of fly ash and of slag, respectively. RFA replacement was fixed at $25 \%$ with two water-cement $(\mathrm{w} / \mathrm{c})$ ratios, as listed in Table 1. Type I Portland cement (specific gravity $=3.15$ ) was used in accordance with American Society for Testing and Materials (ASTM) C150. The saturated surface dry (SSD) specific gravities were as follows: NFA (2.60) and RFA (2.36). The absorptions were as follows: NFA $(2.88 \%)$ and RFA (9.43\%). The maximum size of the coarse aggregates was $13 \mathrm{~mm}$ and the fineness modulus of the fine aggregates was 2.87 .

The coding used to identify "Mix No." in column one of Table 1 is as follows: the first character (4 or 6 ) indicates w/c ratio of 0.4 or 0.6 , respectively. The second character (R) indicates the

Table 1

Mix design $\left(\mathrm{kg} / \mathrm{m}^{3}\right)$.

\begin{tabular}{|c|c|c|c|c|c|c|}
\hline $\mathrm{w} / \mathrm{c}$ & Mix no. & Water & Cement & $\begin{array}{c}\text { Coarse } \\
\text { aggregates }\end{array}$ & $\begin{array}{c}\text { Fine } \\
\text { aggregates }\end{array}$ & RFA \\
\hline \multirow{6}{*}{0.4} & $4 \mathrm{OPC}$ & \multirow{6}{*}{239} & \multirow{6}{*}{525} & \multirow{6}{*}{799} & 614 & 0 \\
\hline & 4RN0 & & & & \multirow{5}{*}{460} & \multirow{5}{*}{154} \\
\hline & $4 \mathrm{RF} 2$ & & & & & \\
\hline & 4RF4 & & & & & \\
\hline & 4RS2 & & & & & \\
\hline & 4RS4 & & & & & \\
\hline \multirow{6}{*}{0.6} & $6 \mathrm{OPC}$ & \multirow{6}{*}{243} & \multirow{6}{*}{350} & \multirow{6}{*}{799} & 739 & 0 \\
\hline & 6RN0 & & & & \multirow{5}{*}{554} & \multirow{5}{*}{185} \\
\hline & $6 \mathrm{RF} 2$ & & & & & \\
\hline & 6RF4 & & & & & \\
\hline & 6RS2 & & & & & \\
\hline & 6RS4 & & & & & \\
\hline
\end{tabular}


inclusion of RFA. The third character (F or S) indicates whether the RFA was coated with fly ash or with slag, respectively. The fourth character $(2,4$, or 0$)$ indicates coating thicknesses of 0.2 , 0.4, or $0 \mathrm{~mm}$, respectively. Finally, OPC refers to ordinary Portland cement used as a control specimen.

\subsection{Specimens and test methods}

A total of $36 \varnothing 100 \times 200 \mathrm{~mm}$ specimens per series (for six mixtures) were cast in this study. Twelve $\varnothing 100 \times 200 \mathrm{~mm}$ specimens per series underwent USV testing (in accordance with ASTM C597) and absorption testing after 7, 14, 28, and $56 \mathrm{~d}$ (in accordance with ASTM C642). Nine $\varnothing 100 \times 200 \mathrm{~mm}$ specimens per series underwent testing for compressive strength after 7, 28, and $56 \mathrm{~d}$ (in accordance with ASTM C39). Three $\varnothing 100 \times 200 \mathrm{~mm}$ specimens per series underwent initial surface absorption tests (ISATs) after $56 \mathrm{~d}$ [in accordance with British Standard (BS) 1881]. Slump tests were conducted (in accordance with ASTM C143). All measurements are presented as the average obtained from three specimens.

\section{Results and Discussion}

\subsection{Slump}

The results of the slump test are listed in Table 2, and slump histograms for all mixtures are presented in Fig. 1. The slump of RFA coated with fly ash had a rising trend of obvious workability owing to the spherical nature of the particles, which acted as a lubricant. The slump increased with the thickness of the fly ash coating, particularly when the w/c ratio was set at 0.6.

Figure 1 presents the slump test results obtained from RFA coated with slag. In these specimens, the amount of slump decreased with an increase in the thickness of the RFA coating, particularly in specimens with a w/c ratio of 0.6. These results can be attributed to the irregular shape of the slag particles. RFA coated with old cement paste required more water than did the control specimens to reach the same amount of slump.

Table 2

Results of slump test of specimens in which fly ash was used to wrap fiber reinforced concrete (FRC) aggregates.

\begin{tabular}{lc}
\hline Mix no. & Slump $(\mathrm{cm})$ \\
\hline 4OPC & 15.5 \\
4RN0 & 14 \\
4RF2 & 13.2 \\
4RF4 & 15.5 \\
4RS2 & 14 \\
4RS4 & 10.6 \\
6OPC & 18 \\
6RN0 & 16.2 \\
6RF2 & 17.5 \\
6RF4 & 21.3 \\
6RS2 & 19.5 \\
6RS4 & 14.3 \\
\hline
\end{tabular}




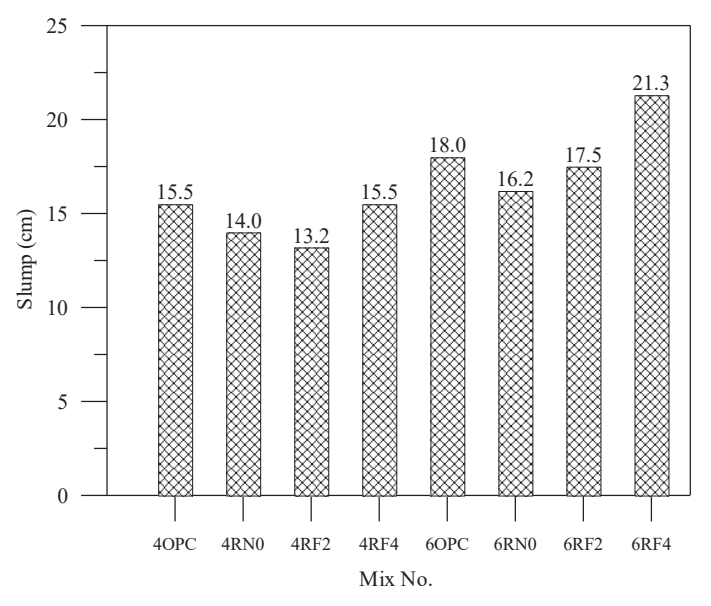

(a)

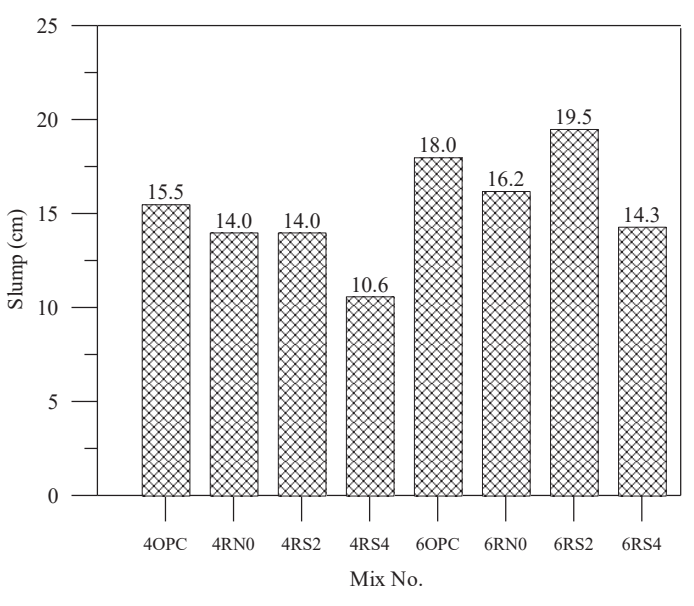

(b)

Fig. 1. Slump test histograms of specimens using fly ash to wrap FRC aggregates. (a) RFA coated with fly ash and (b) RFA coated with slag.

\subsection{Compressive strength}

The compressive strength results from fly-ash-coated RFA are summarized in Table 3. These specimens were shown to have compressive strength lower than that of the control specimens. Increasing the coating thickness from 0.2 to $0.4 \mathrm{~mm}$ significantly reduced the compressive strength. The compressive strength of the specimens after $28 \mathrm{~d}$ was as follows: OPC specimens (36 MPa), 25\% RFA without coating (41 MPa). These results are consistent with those in the literature. ${ }^{(3)}$ After $7 \mathrm{~d}$, the RFA with a $0.2 \mathrm{~mm}$ coating of fly ash had greater compressive strength than the control specimens; however, the difference narrowed over time. After $7 \mathrm{~d}$, the compressive strength of the RFA with a $0.4 \mathrm{~mm}$ coating of fly ash was far below that of the control specimens. Replacing the natural aggregates with RFA did not increase the compressive strength of the specimens. Coating the RFA specimens with fly ash also had little effect on the compressive strength. Specimens with $25 \%$ uncoated recycled concrete and a higher $\mathrm{w} / \mathrm{c}$ ratio lacked the strength of the control specimens. The compressive strength of RFA coated with fly ash was lower than those of the control specimens and uncoated RFA specimens, regardless of the coating thickness.

The compressive strength results from slag-coated RFA are summarized in Table 4. The compressive strength of these specimens was shown to increase with the thickness of the coating. The compressive strength of the specimens after $28 \mathrm{~d}$ was as follows: $36.34 \mathrm{MPa}$ (control specimens) and $41.17 \mathrm{MPa}$ (uncoated RFA specimens). After $7 \mathrm{~d}$, the compressive strength of the slag-coated RFA did not differ significantly from that of the control group; however, after 28 $\mathrm{d}$, the strength of the slag-coated specimens (40 MPa) exceeded that of the control by $10.07 \%$. After $56 \mathrm{~d}$, the compressive strength of the slag-coated RFA $(0.2 \mathrm{~mm})$ was $9.43 \%$ higher than that of the uncoated RFA but $2.97 \%$ lower than that of the control. The compressive strength of the slag-coated RFA $(0.4 \mathrm{~mm})$ exceeded the control by $8.65 \%$, as well as the uncoated RFA by $22.55 \%$. Clearly, the addition of slag can be used to improve the compressive strength of RFA, 
Table 3

Compressive strength results for RFA coated with fly ash.

\begin{tabular}{llll}
\hline \multirow{2}{*}{ Mix no. } & \multicolumn{3}{c}{ Compressive strength (MPa) } \\
\cline { 2 - 4 } & $7 \mathrm{~d}$ & $28 \mathrm{~d}$ & $56 \mathrm{~d}$ \\
\hline 4OPC & 31.76 & 36.34 & 48.07 \\
4RN0 & 30.95 & 41.17 & 42.62 \\
4RF2 & 35.49 & 36.77 & 41.14 \\
4RF4 & 26.9 & 33.42 & 35.76 \\
6OPC & 22.53 & 27.27 & 34.7 \\
6RN0 & 17.65 & 23.63 & 27.02 \\
6RF2 & 19.08 & 23.99 & 30.36 \\
6RF4 & 14.86 & 22.54 & 30.75 \\
\hline
\end{tabular}

Table 4

Compressive strength results for slag-coated RFA.

\begin{tabular}{lccl}
\hline \multirow{2}{*}{ Mix no. } & \multicolumn{3}{c}{ Compressive strength (MPa) } \\
\cline { 2 - 4 } & $7 \mathrm{~d}$ & $28 \mathrm{~d}$ & $56 \mathrm{~d}$ \\
\hline 4OPC & 31.76 & 36.34 & 48.07 \\
4RN0 & 30.95 & 41.17 & 42.62 \\
4RS2 & 32.86 & 40.17 & 46.64 \\
4RS4 & 33.67 & 43.33 & 52.23 \\
6OPC & 22.53 & 27.27 & 34.7 \\
6RN0 & 17.65 & 23.63 & 27.02 \\
6RS2 & 22.49 & 36.52 & 37.8 \\
6RS4 & 33.67 & 39.68 & 45.48 \\
\hline
\end{tabular}

and the effects increase with the thickness of the coating, as follows: $0.2 \mathrm{~mm}(+8.93 \%)$ and 0.4 $\mathrm{mm}(+31.06 \%)$, compared with the control specimens. Increasing the $\mathrm{w} / \mathrm{c}$ ratio had no effect on the development of compressive strength in any of the mixes using the slag-coated RFA.

\subsection{USV}

USV measurement is a nondestructive test used to assess the quality of freshly poured and existing concrete structures. USV measurements use wave propagation behavior to determine the internal uniformity and compactness of the concrete. Wave propagation theory posits that the transmission rate of sound waves is determined by the elastic modulus and the density of the material. Ultrasonic waves bypassing cracks in the concrete increases the transfer time of the waves.

Figure 2 lists the USV results obtained from cylindrical specimens of fly-ash-coated RFA specimens after 7, 14, 28, and $56 \mathrm{~d}$. We did not observe a significant difference in USV between fly-ash-coated RFA and the control specimens. The USV of specimens with $0.2 \mathrm{~mm}$ coating exceeded that of the specimens with a $0.4 \mathrm{~mm}$ coating, but was still lower than those of the OPC specimens and specimens of uncoated recycled concrete. We determined that the pozzolanic reactivity of fly ash after $28 \mathrm{~d}$ was a slower reaction, which hindered the development of internal pores. The USV of RFA coated with fly ash was lower than that of ordinary concrete and concrete made with uncoated RFA. These results indicate that coating RFA with fly ash exerts no significant effect with regard to the compactness of the resulting concrete.

Varying the w/c ratio was shown to have a significant effect on USV measurements. The higher the coated thickness of RFA with fly ash, the worse the improvement of USV. When the w/c ratio was higher, coating the RFA with fly ash was shown to increase the USV beyond that of the control specimens, owing to an increase in the number of fine pores.

Figure 3 lists the USV results obtained from cylindrical specimens of slag-coated RFA specimens after 7, 14, 28, and $56 \mathrm{~d}$. Overall, the USV of slag-coated RFA was higher, and the effects of the slag coating increased with thickness. The USV of specimens with a $0.2 \mathrm{~mm}$ coating exceeded by $1 \%$ that of the control specimens. After $56 \mathrm{~d}$, the USV of specimens with 


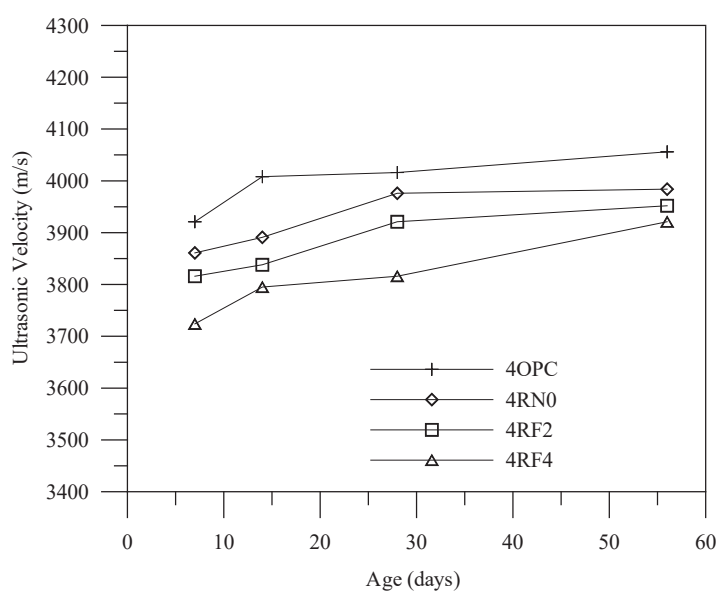

(a)

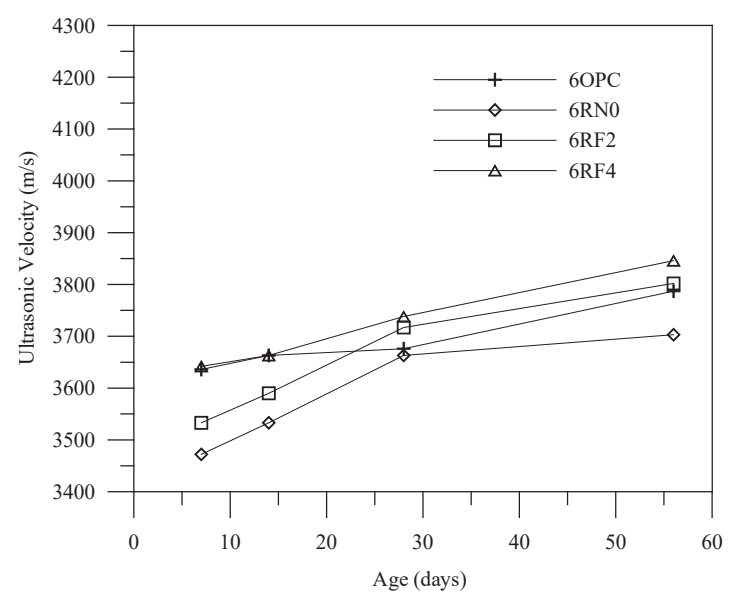

(b)

Fig. 2. USV curves of specimens containing RFA coated with fly ash. (a) w/c ratio $=0.4$ and (b) w/c ratio $=0.6$.

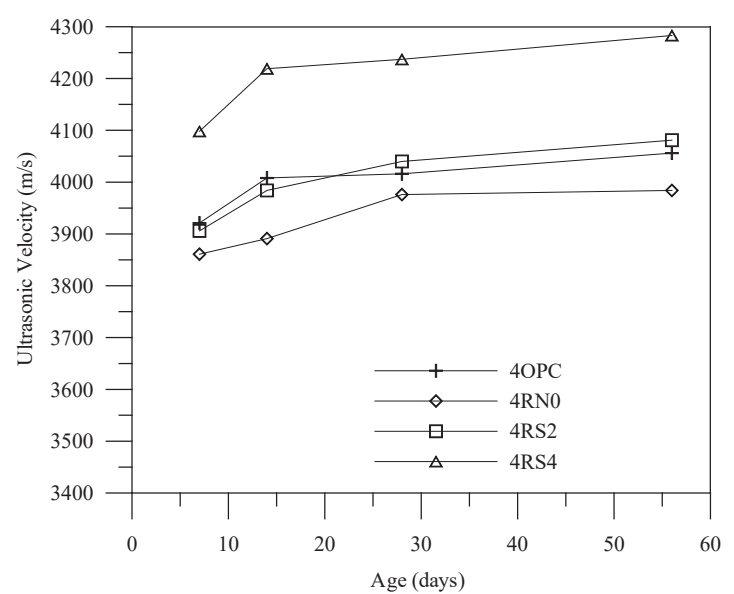

(a)

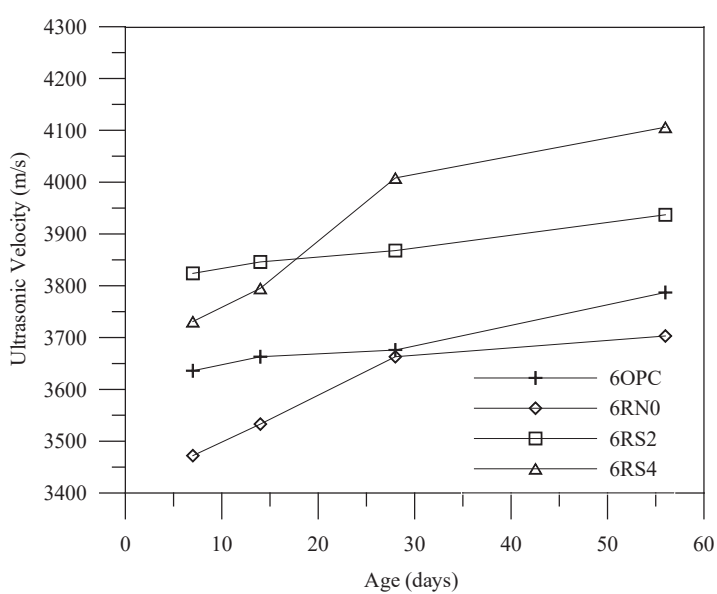

(b)

Fig. 3. USV curves of specimens containing slag-coated RFA. (a) $w / c$ ratio $=0.4$ and (b) $w / c$ ratio $=0.6$.

$0.4 \mathrm{~mm}$ coating exceeded that of ordinary concrete by $5.6 \%$ and that of recycled concrete by $7.5 \%$. This can be attributed to the filling of internal pores with hydration products following a reaction among the slag particles, cement particles, and aggregates.

Coating the RFA with slag had a significant effect on USV; however, this was not mediated by w/c ratio. As shown in Fig. 3, an increase in the thickness of the slag coating significantly increased the USV beyond that of the control specimens. After $56 \mathrm{~d}$, the USV of specimens with a $0.2 \mathrm{~mm}$ coating exceeded that of ordinary concrete by $3.96 \%$ and that of uncoated recycled concrete by $6.32 \%$. The USV of specimens with a $0.4 \mathrm{~mm}$ coating exceeded that of the control by $8.42 \%$ and that of uncoated recycled concrete by $10.88 \%$. These effects can be attributed to the pozzolanic reaction between the slag and cement, which resulted in the formation of microstructures within the internal pores to produce specimens of greater compactness. 


\subsection{Absorption}

Saturated water absorption is affected by w/c ratio as well as pozzolanic materials. Saturated water absorption is not directly related to compressive strength; however, it is affected by the capillary pores, the connectivity of pore networks, and colloid development.

As shown in Table 5, the absorption of all specimens with fly-ash coatings decreased gradually with increasing age. Absorption by uncoated recycled concrete exceeded that by ordinary concrete. The uncoated recycled concrete was also less compact than ordinary concrete. After $56 \mathrm{~d}$, the absorption of specimens with $0.2 \mathrm{~mm}$ coatings was $20.65 \%$ lower than that of uncoated recycled concrete; however, it was $2.5 \%$ higher than that of ordinary concrete. The absorption of specimens with $0.4 \mathrm{~mm}$ coatings was $47.5 \%$ higher than that of ordinary concrete, which was in turn $14.19 \%$ higher than that of uncoated recycled concrete. These results indicate that coating the RFA with fly ash increased the absorption of water.

Even when the w/c ratio was lower, coating the RFA with fly ash increased absorption; however, the effect became less pronounced as the thickness of the coating was increased. The control specimen had the lowest absorption. The absorption of specimens with $0.2 \mathrm{~mm}$ coatings was lower than that of the uncoated recycled concrete but higher than that of ordinary concrete. The absorption of specimens with $0.4 \mathrm{~mm}$ coatings was also higher than those of all the mixtures. The slow pozzolanic reaction resulted in the slow development of pore structures, and ITZ became looser and more porous.

As shown in Table 6, the absorption of specimens containing slag-coated RFA was lower than that of the control group. The absorption of specimens with $0.4 \mathrm{~mm}$ slag coatings was slightly higher than that of the control group after $7 \mathrm{~d}$. These results indicate that coating RFA with slag could fill the specimen and ITZ pores and decrease the absorption in an agedependent manner. Thicker slag coatings on the RFA resulted in lower absorption (regardless of w/c ratio), owing to the enhanced pozzolanic reaction and the formation of microstructures within the pores.

\subsection{ISAT}

The ISAT can be used to assess the surface properties of cement-based materials and the effect of the pores in transmitting water molecules via capillary action. The amount of water

Table 5

Absorption results for fly-ash-coated RFA.

\begin{tabular}{lclll}
\hline \multirow{2}{*}{ Mix no. } & \multicolumn{4}{c}{ Absorption (\%) } \\
\cline { 2 - 5 } & $7 \mathrm{~d}$ & $14 \mathrm{~d}$ & $28 \mathrm{~d}$ & $56 \mathrm{~d}$ \\
\hline 4OPC & 5.03 & 4.91 & 4.67 & 3.6 \\
4RN0 & 5.65 & 5.59 & 5.37 & 4.65 \\
4RF2 & 5.38 & 4.74 & 4.65 & 3.69 \\
4RF4 & 6.79 & 5.9 & 5.66 & 5.31 \\
6OPC & 6.26 & 5.92 & 5.46 & 4.56 \\
6RN0 & 7.56 & 7.5 & 7.24 & 6.18 \\
6RF2 & 6.82 & 6.69 & 6.6 & 6.33 \\
6RF4 & 7.96 & 7.4 & 6.64 & 6.32 \\
\hline
\end{tabular}

Table 6

Absorption results for slag-coated RFA.

\begin{tabular}{lcccc}
\hline \multirow{2}{*}{ Mix no. } & \multicolumn{4}{c}{ Absorption (\%) } \\
\cline { 2 - 5 } & $7 \mathrm{~d}$ & $14 \mathrm{~d}$ & $28 \mathrm{~d}$ & $56 \mathrm{~d}$ \\
\hline 4OPC & 5.03 & 4.91 & 4.67 & 3.60 \\
4RN0 & 5.65 & 5.59 & 5.37 & 4.65 \\
4RF2 & 4.16 & 4.13 & 3.90 & 3.33 \\
4RF4 & 5.06 & 4.28 & 3.23 & 2.01 \\
6OPC & 6.26 & 5.92 & 5.46 & 4.56 \\
6RN0 & 7.56 & 7.50 & 7.24 & 6.18 \\
6RF2 & 5.85 & 5.79 & 5.34 & 5.03 \\
6RF4 & 5.27 & 4.32 & 3.90 & 2.62 \\
\hline
\end{tabular}


absorbed per unit area is measured over a specified period of time, in accordance with the specification outlined in BS 1881. Table 7 presents the concrete penetration index proposed by Kumar and Bhattacharjee, ${ }^{(12)}$ by which the permeability of test specimens can be evaluated. The results of ISAT measurements are presented in Figs. 4 and 5.

When using a lower w/c ratio, the control specimens and specimens containing fly-ashcoated RFA both presented high permeability. The ISAT value of the specimens with $0.2 \mathrm{~mm}$

Table 7

Concrete penetration index.

\begin{tabular}{lccc}
\hline \multirow{2}{*}{ Time $(\mathrm{min})$} & \multicolumn{3}{c}{ Concrete penetration index $\left(\mathrm{ml} / \mathrm{m}^{2} \mathrm{~s}\right)$} \\
\cline { 2 - 4 } & Low & Medium & High \\
\hline 10 & $<0.25$ & $0.25-0.50$ & $>0.50$ \\
30 & $<0.17$ & $0.17-0.35$ & $>0.35$ \\
60 & $<0.07$ & $0.10-0.20$ & $>0.20$ \\
\hline
\end{tabular}

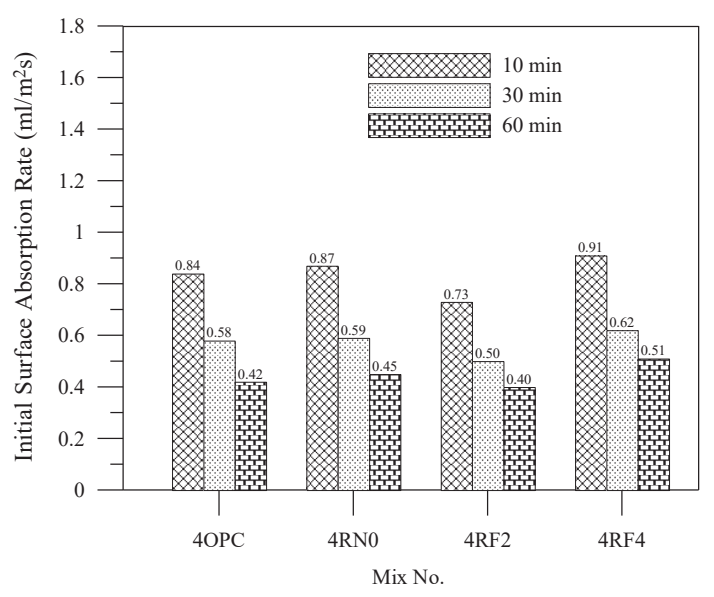

(a)

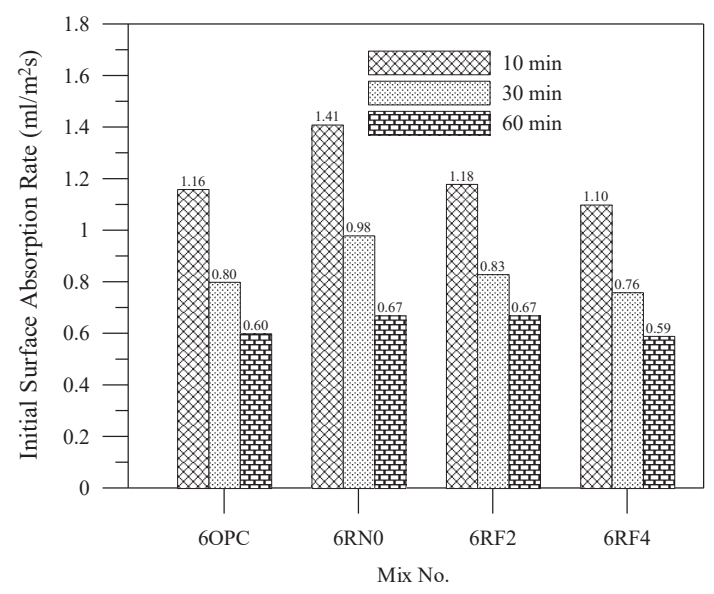

(b)

Fig. 4. ISAT curves of specimens containing RFA coated with fly ash. (a) $w / c$ ratio $=0.4$ and (b) w/c ratio $=0.6$.

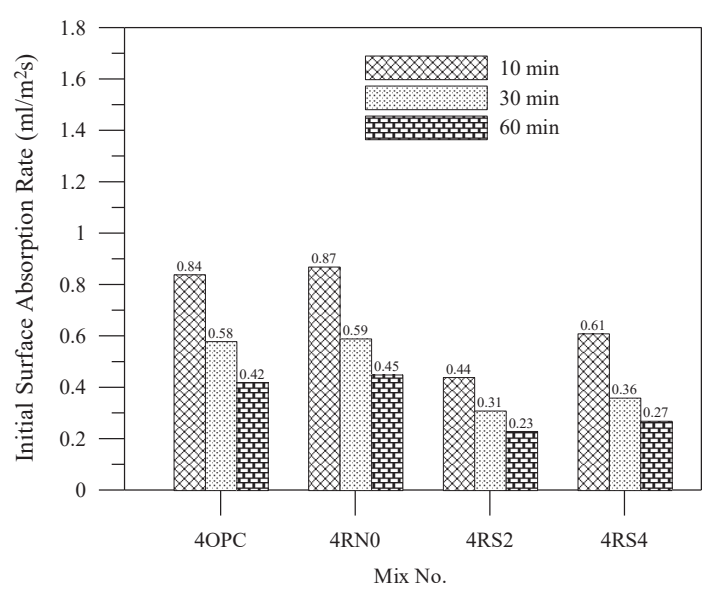

(a)

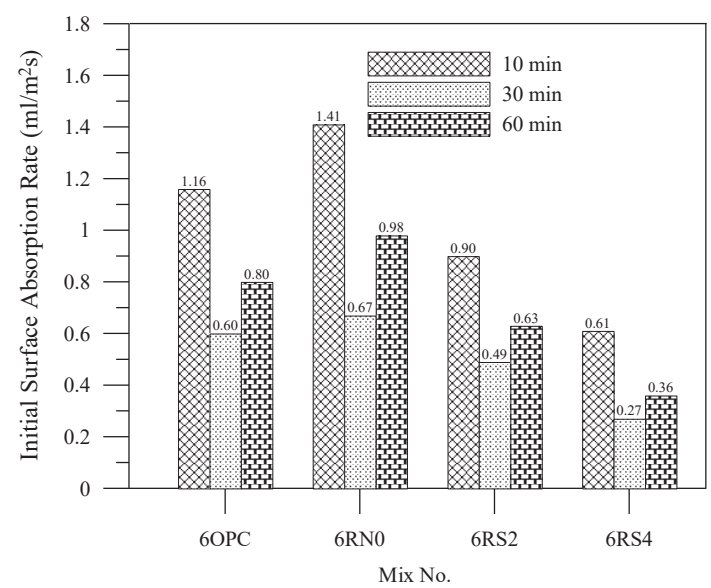

(b)

Fig. 5. ISAT curves of specimens containing slag-coated RFA. (a) $w / c$ ratio $=0.4$ and (b) $w / c$ ratio $=0.6$. 
fly ash coatings was lower than that of the control specimens; however, that of the specimens with $0.4 \mathrm{~mm}$ coatings was higher that of the control. Fly ash main strength development occurred at a later age and the Pozzolanic reaction had not been completed, which caused low microstructure porosity.

As shown in Fig. 5, the ISAT value of the specimens with a higher w/c ratio was higher than that of the specimens with a lower w/c ratio; i.e., they both presented high permeability. The ISAT value of specimens with slag-coated RFA was lower than that of uncoated recycled concrete. The ISAT values of specimens with $0.2 \mathrm{~mm}$ slag-coated RFA indicated medium permeability. The specimens with $0.4 \mathrm{~mm}$ slag-coated RFA were more permeable; however, the ISAT value was lower than that of the control specimens. This is an indication that filling the pores led to a decrease in the ISAT value, regardless of the w/c ratio. Specimens with slag-coated RFA improved the permeability and the values decreased with an increase in the thickness of the slag coating to far below that of the control group.

\section{Conclusions}

1. Coating RFA with fly ash was shown to improve the workability of the concrete owing to the bearing effect, regardless of the w/c ratio, and the effect increased with the thickness of the coating. Coating RFA with slag was shown to reduce the workability of the concrete, owing to the absorption of water by the slag.

2. Coating RFA with fly ash was shown to slightly increase the compressive strength of the concrete; however, the specimens still failed to match the strength of the original concrete. Coating RFA with slag greatly improved compressive strength, actually exceeding that of the original concrete. The effect of the slag on compressive strength was shown to increase with the thickness of the coating.

3. Coating RFA with slag was shown to increase the USV beyond that of the control specimens and specimens with fly-ash-coated RFA, regardless of the w/c ratio. The effect of the slag on the USV increased with the thickness of the coating.

4. Coating RFA with fly ash had no effect on absorption or ISAT value, compared with the control specimens. Coating RFA with slag reduced absorption and ISAT values to below those of the control. This is an indication that coating RFA with slag fills the pores and, in so doing, reduces absorption in accordance with the thickness of the coating.

\section{Acknowledgments}

The author is grateful to Mr. Bo-Sheng Syu who assisted with this study.

\section{References}

1 C. C. Fan, R. Huang, H. Hwang, and S. J. Chao: Mater. 8 (2015) 2658.

2 J. Han, W. Liu, S. Wang, D. Du, F. Xu, W. Li, and G. D. Schutter: Constr. Build. Mater. 128 (2016) 256.

3 B. Singh, M. R. Rahman, R. Paswan, and S. K. Bhattacharyya: Constr. Build. Mater. 118 (2016) 171.

4 Q. Chen, H. Zhu, Z. Yan, J. W. Jue, Z. Jiang, and Y. Wang: Constr. Build. Mater. 114 (2016) 839. 
5 Y. Mohammadi, R. Carkon-Azad, S. P. Singhb, and S. K. Kaushik: Constr. Build. Mater. 23 (2009) 183.

6 Y. Senhadji, G. Escadeillas, M. Mouli, and H. Khelafi: Powder Technol. 254 (2014) 314.

7 K. Wu, H. Shi, L. Xu, G. Ye, and G. D. Schutter: Cem. Concr. Res. 79 (2016) 243.

8 T. Plagué, C. Desmettre, and J. P. Charron: Cem. Concr. Res. 94 (2017) 59.

9 N. Fonseca, J. de Brito, and L. Evangelista: Cem. Concr. Comp. 33 (2011) 637.

10 W. C. Choi and H. D. Yun: Eng. Struct. 41 (2012) 285.

11 S. Ismail and M. Ramli: Constr. Build. Mater. 44 (2013) 464.

12 R. Kumar and B. Bhattacharjee: Cem. Concr. Res. 34 (2004) 321.

\section{About the Author}

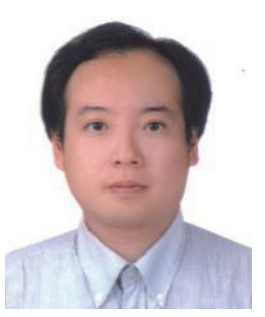

Wei-Ting Lin received his M.S. and Ph.D. degrees from the Department of Harbor and River Engineering, National Taiwan Ocean University, Taiwan, in 2001 and 2009, respectively. He is an Assistant Professor in the Department of Civil Engineering, Ilan University, Taiwan. His research interests include structural engineering, seismic behavior and testing, cement-based composites, durability, corrosion engineering, and construction waste treatment. 